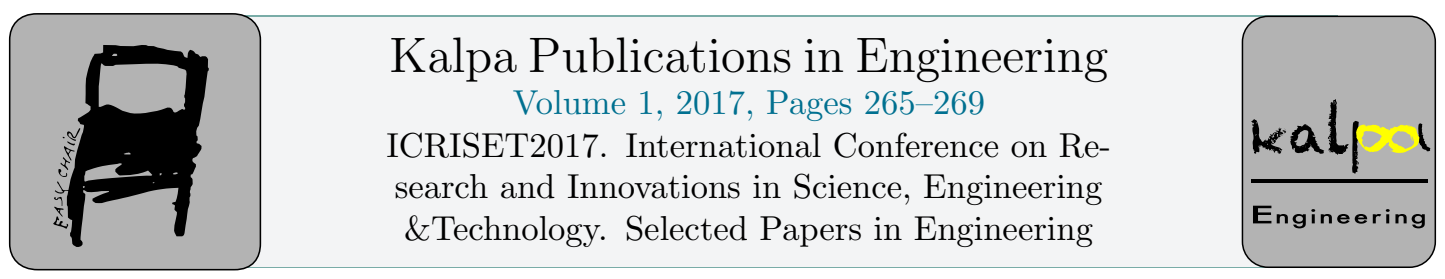

\title{
Short Distance Wireless Power Transfer for Small devices
}

\author{
Parth S. Panchal ${ }^{1}$ and A.A.Shaikh ${ }^{2}$ \\ ${ }^{1}$ Student, BVM Engineering College V.V.Nagar, India \\ ${ }^{2}$ Associate Professor, BVM Engineering College V.V.Nagar, India \\ parthpanchal964@gmail.com, abdulsalam78@yahoo.com
}

\begin{abstract}
There are many small devices like cell phone, which requires small amount of power for charging their battery. The large numbers of these devices in use has resulted into substantial amount of power consumption. The wiring installation to cater to this demand has becomes complex and inconvenient. Wireless power transmission to such gadgets can relieve the wiring system and increase the comfort level of the user. This paper discusses an experimental set up which was successfully designed and tested for charging of battery of small devices like cell phone.
\end{abstract}

\section{Introduction}

Wireless power transfer is the transfer of electrical power from one place to another place without any manmade conductor. Nikola Tesla was an imaginative pioneer in the field of science and technology who through used wireless power transmission to illuminate 200 bulbs which were placed at a distance $40 \mathrm{~km}$ away. He made a coil called resonant transformer or tesla coil but its electrical field was dispersed. Presently the use of electronic devices is increasing exponentially and operation of most of these devices necessitate use of battery. The most common device is cell phone which is extensively use by growing number of people across the globe. Battery is heart of the cell phone or remote handset which requires frequent recharging. Ordinary chargers of battery include rectifier, filter and USB cable of fixed length, which indirectly reduces the mobility of the mobile during charging. 


\section{Experimental Set-up:-}

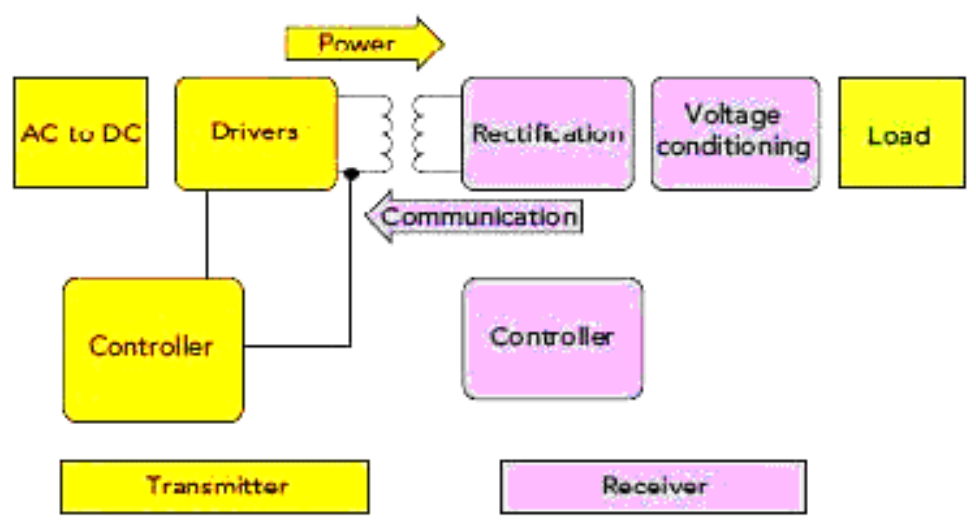

Fig-1 Block diagram of Wireless Power Transfer

This paper discuss a technique which includes short range of WPT. Figure-1 shows block diagram of a typical wireless power transfer. The input power fed to the transmitter is converted from AC into DC by rectification. This de voltge is then converted into ac of variable frequency. This high frequency ac power is feed in transmitter coil. When it will happen coil generate electromagnetic field which same as supply frequency it is shown in diagram. The receiver coil receive this transmitted power at higher frequency and hence it cannot be fed directly to the load. Thus after rectification this power is given to voltage regulator which controls the voltage to prevent any harm to the load. A communication between the reciever output and transmitter input is establlished so that once the required level of power is transmitted to the load, the transmition should be stopped through the controller, otherwise the excessive supply of power will damage or affect the life of the load. The efficiency of power transmission is inversly proportional to distance between the transmitter and the receiver i.e. load.

\section{The Transformer Circuit:-}

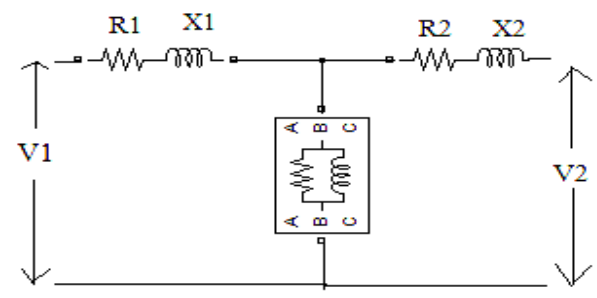

Fig-2 Equivalent circuit of Transformer 
In equivalent circuit of transformer shown above, $R_{1} \& X_{1}$ is primary resistance and reactance where voltage is $V_{1}$ and $V_{2}$ are input and output voltage respectively. If inductive coupling is used for higher frequency then $\mathrm{X}_{1}$ becomes very high which results into very high voltage drop across it and voltage transmission (i.e. $\mathrm{V}_{2}$ ) gets reduced drastically.

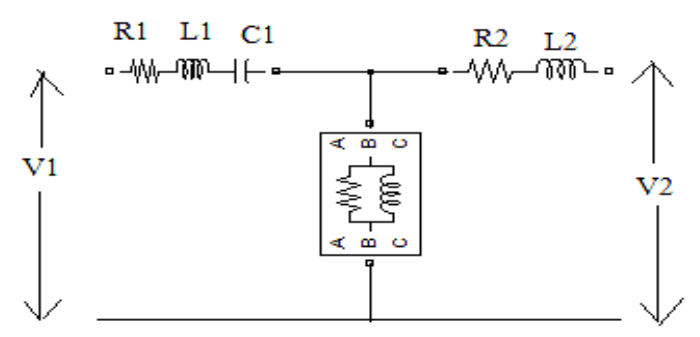

Fig-3 Effect of Capacitor

To eliminate this effect a capacitor in When a capacitor of specific value is connected in series with the inductor, at resonant frequency $\left(f_{o}=1 /\left[2 \pi(L C)^{1 / 2}\right]\right), X_{L}=X_{C}$. The voltage drop across the remnant resistor will decrease, resulting into increased output voltage $\left(\mathrm{V}_{2}\right)$. It is known as resonators.

Frequency $=1 \mathrm{kHz}$, Thus value of coil and capacitor is $\mathrm{L}=2.3 \mathrm{mH}$ and $\mathrm{C}=10 \mathrm{uF}$ respectively.

\section{Transmitter Circuit:-}

As per aforementioned concept, transmitter circuit is used to generate high frequency magnetic field. To convert the d.c. voltage of the battery into high frequency ac, voltage source inverter is used. In the inverter circuit power switch MOSFETs are used because of their capability to handle high frequencies operation. For better performance H-bridge inverter configuration is used. In the circuit $12 \mathrm{~V}$ d.c. is given as an input. Four MOSFETs (IRZ44) capable of handling 40A current, are used in the inverter circuit. Pulse generator is used to trigger MOSFET.. Operation of inverter is done by triggering different pairs of MOSFETs (MOSFET \& MOSFET3 and MOSFET1 \& MOSFET2) at specific time with some time delay between triggering of each pair, so that we get specific voltage and frequency. This entire circuit shown below was simulated in matlab.

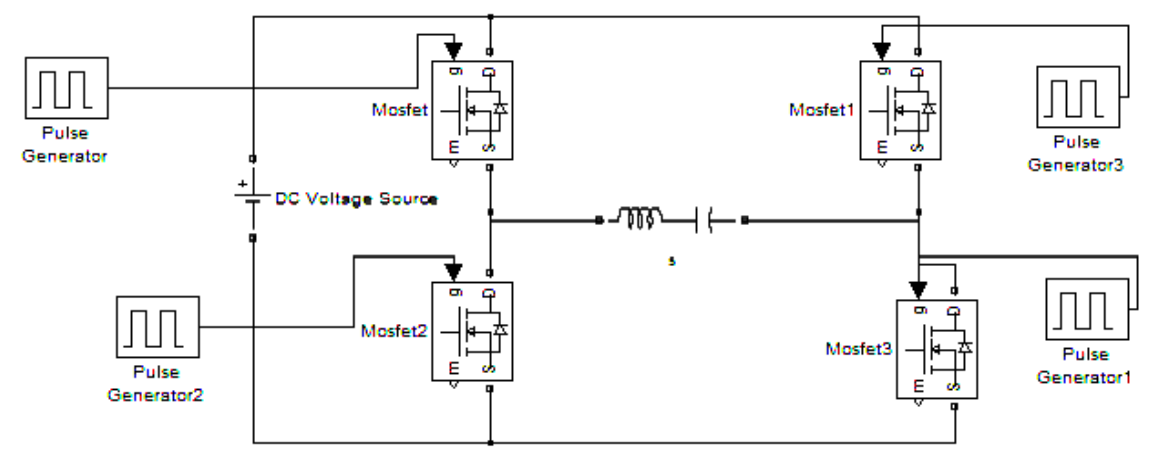

Fig:-4 H bridge Inverter using MOSFET 


\section{Receiver Circuit}

Transmitter coil generate magnetic field at higher frequency so, receiver circuit is designed so as to get higher efficiency. Litz wire is a type of cable used to carry high frequency a.c. This wire is designed to reduce the skin effect and proximity effect losses in conductor used at frequencies up to about $1 \mathrm{MHz}$. Thus litz wire is used for designing tranmitter coil so that the power is transmitted faithfully at the maximum efficiency. Some other factors to be considered while considering efficiency of transmission.

Coupling factor:- coupling factor is defined as positioning of primary coil and secondary coil. Efficiency will decrease when distance between primary coil and secondary coil is increased and thus to obtain maximum efficiency coupling factor should be 1 .

Resonance frequency:- This is the frequency at which voltage magnification occurs and we get maximum output. This frequency was selected as $1 \mathrm{kHz}$.

At receiver side, a capacitor was connected in parallel to the receiver coil, which reduces the equivalent impedance coil, and the required current can be achieved. This high frequency supply of the coil is rectified by using Schottky diode, which is best suited for fast switching applications. Suitable filter circuit will convert the pulsating dc. to pure dc. This smooth dc. is given to the mobile phone for charging its battery.

\section{Result \& Analysis:-}

When current is passed through the inductor, it generates electromagnetic field which is at high frequency. Waveform of voltage, which is across to inductor which amplitude is $5 \mathrm{v}$ and frequency, is $1 \mathrm{kHz}$ as shown below.

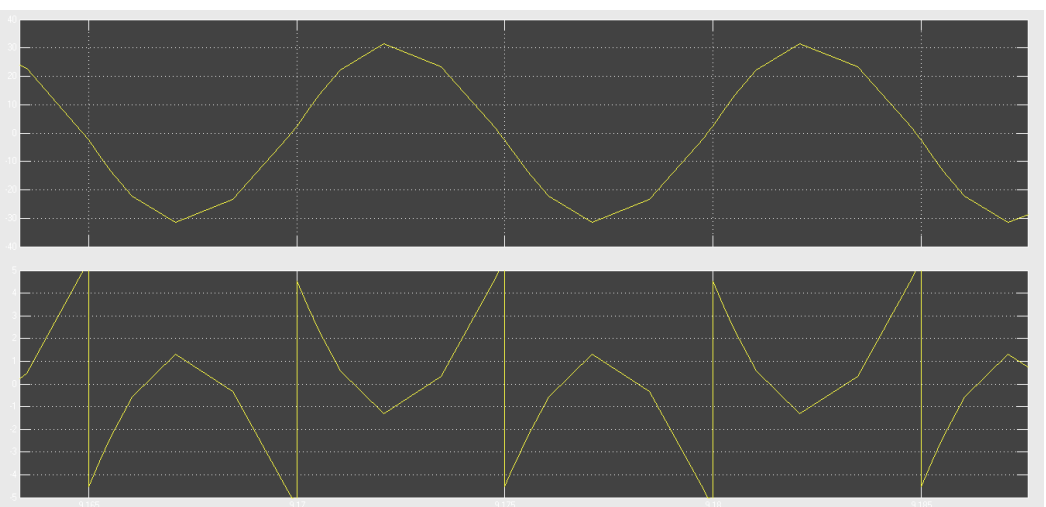

Fig:-5 MATLAB Simulation and Result 
The receiver can deliver a load current of $271 \mathrm{~mA}$ at $5.2 \mathrm{~V}$ constant voltage. Therefore approximate output power $=5.2 \mathrm{~V} * 271 \mathrm{~mA}=1.4 \mathrm{~W}$, and power consumption of transmitter = $12 \mathrm{~V}^{*} 180 \mathrm{~mA}=2.16 \mathrm{~W}$. So efficiency $=$ output power/input power $=64.8 \%$

\section{Advantages \& Disadvantages}

Simple, efficient, shock proof, cost effective and ease in use are some of the main advantages of this device. While other methods used for charging cell phone are restricted to only if Qi enabled technology is embedded in the phone, the method suggested in this paper can be used to charge any cell phone wirelessly. The demerits are that presently it can be used for charging only cell phone upto a restricted distance. Secondly, electromagnetic field generated by the circuit may result into eddy current loss in adjacent devices.

\section{Conclusion}

The requirement of efficient power transmisson is growing exponentially and simultaneously its wiring is becoming more and more complex. Wireless power transmission is a solution to growing problem. Short to long range wireless power transmission are coming into existence. However the system can be relieved further if low power deviced can be catered their power requirement wirelessly. A successful attempt was made to charge the cell phone remotely. The number of devices and distance of power transmission can be enhanced with proper used of this method.

\section{References}

Electrical Machine by I.J.Nagrath and D.P.Kothari.

Gayakwad Ramakant, (2014). Op-Amp and Linear IC, Prentice Hall

Power Electronics by P.S.Bhimbhra.

Electrical Machine Design by A.K.Sawhney.

$\underline{\text { http://witricity.com/ }}$

General Electric New Room, http://www.genewsroom.com 